\title{
Impact of $\mathrm{Bi}_{2} \mathrm{O}_{3}$ modifier concentration on barium-zincborate glasses: physical, structural, elastic, and radiation-shielding properties
}

\author{
K. A. Naseer ${ }^{1}$, K. Marimuthu ${ }^{1, \mathrm{a}} \mathbb{D}$, K. A. Mahmoud ${ }^{2,3}$, M. I. Sayyed ${ }^{4,5}$ \\ ${ }^{1}$ Department of Physics, Gandhigram Rural Institute - Deemed to be University, Gandhigram 624 302, India \\ ${ }^{2}$ Ural Federal University, St. Mira, 19, Yekaterinburg, Russia 620002 \\ ${ }^{3}$ Nuclear Materials Authority, Maadi, Cairo, Egypt \\ ${ }^{4}$ Department of Physics, Faculty of Science, Isra University, Amman, Jordan \\ 5 Department of Nuclear Medicine Research, Institute for Research and Medical Consultations (IRMC), Imam \\ Abdulrahman bin Faisal University (IAU), Dammam, Saudi Arabia
}

Received: 17 October 2020 / Accepted: 26 December 2020

(C) The Author(s), under exclusive licence to Società Italiana di Fisica and Springer-Verlag GmbH Germany, part of Springer Nature 2021

\begin{abstract}
A sequence of $\mathrm{Bi}_{2} \mathrm{O}_{3}$ varying barium-zincborate (BZX) glasses with the chemical composition (60- $x$ ) $\mathrm{B}_{2} \mathrm{O}_{3}-20 \mathrm{ZnO}-20 \mathrm{BaCO}_{3}-x \mathrm{Bi}_{2} \mathrm{O}_{3}-0.5 \mathrm{Dy}_{2} \mathrm{O}_{3}$ (where $x=0,5,10,15,20$, 25 , and 30 in $\mathrm{wt} \%$ ) is fabricated by melt-quenching method. The fabricated samples were examined for the variation in physical, structural, elastic, and radiation-shielding properties with the $\mathrm{Bi}_{2} \mathrm{O}_{3}$ concentration. The structural and compositional evaluations are done using XRD and FTIR spectra. The BZX matrixes consist of the trigonal-planar and tetrahedral groups of borates, $\mathrm{BiO}_{3}$ and $\mathrm{BiO}_{6}$ units of $\mathrm{Bi}_{2} \mathrm{O}_{3}$, and the non-bridging oxygen in general. The average single-bond strength values substantiate the increasing ionic nature of the BZX glasses. The variation in the density and molar volume of the BZX series discussed in terms of various structural and elastic properties. The glass-coded BZ15 was found to be the best candidate for the sound-resistant applications based on the atomic packing fraction and the acoustic impedance studies. With MCNP5 simulation, the mass attenuation coefficient (MAC) values of all the samples were calculated and compared with a theoretical approach using the XCOM program. As the amount of $\mathrm{Bi}_{2} \mathrm{O}_{3}$ increases, the linear attenuation coefficient (LAC) increases with it at all energies. The LAC values varied between 0.2805 and $0.5269 \mathrm{~cm}^{-1}$ for the investigated glasses at $0.81 \mathrm{MeV}$. BZ30 glass is the more effective shield due to the highest MAC and LAC values.
\end{abstract}

\section{Introduction}

The global populace is growing, and the drastic industrialization in developing nations multiplied humankind's strive after energy by an exceptional amount. The more significant part of our energy originates from petroleum derivatives dig out from deep inside the Earth's crust. Over the past centuries, fossil fuels' use elevates the greenhouse gas level in the atmosphere, which is inextricably linked with climate change like global warming. The scientists around

\footnotetext{
a e-mail: mari_ram2000@yahoo.com (corresponding author)
} 
the globe are unanimously challenging the people to wean off the fossil fuel habit. One of the tremendous difficulties the planet facing is this transformation toward a clean energy source which can slash the $\mathrm{CO}_{2}$ emission. We have several renewable energy sources like solar energy, wind energy, tide energy, etc. But the problem is the amount of energy we are using in our day-to-day life is more than a million tera-joules. Even the largest nuclear power plant (NPP) (Kashiwazaki-Kariwa NPP) cannot provide that much energy in around five years. One of the solutions to meet this energy requirement is to build several NPPs, but NPPs are always at stake because of the safety concern. Some developed countries like Japan and Germany have decided to shut down their nuclear industry after Fukushima's tragic disaster in 2011 [1]. And many countries have turned down the appraisal for replacing the existing reactors. The world is moving on from Fukushima now and looking for improved NPP designs. The commercial NPP industry started flourishing again as a solution for the long-known reality of the rising energy demand. 'NuScale Power', a company in the USA, introduced a new NPP design called small modular reactor (SMR), the next generation of NPP. The company managed to pass the fourth phase of the review of SMR by the US Nuclear Regulatory Commission, which is their first of a kind certification. The rest of the world is not different from this. Russia has already commenced a floating SMR in the Arctic Ocean; China announced SMR projects years before, and the UK also invested in a vast amount of money in SMR projects [2,3].

Despite being small-sized, SMR also may go through similar issues as its bigger versions, particularly safety issues. There comes the relevance of research activities related to shielding materials. Nowadays, nuclear energy has a crucial role not only in energy production but also in medical, national security, and agricultural applications. The technicians and the people around the area are under immense threat of radiation exposure. As in any other industry, the mishaps in the nuclear industry also can be avoided or reduced to a minimal level by accurate designing and implementation. Despite being the source of skepticism, most of the scientists around the globe are working hard for making the nuclear industry a safer place. They keep on working on the safer NPP designs and trying to invent advanced protective layers for those who are related to the industry. To be protected from these extremely penetrating and ionizing radiations like $\mathrm{X}$-rays and gamma-rays ( $\gamma$-rays) is a grand challenge in this industry. For that, the NPP should be covered by a solid fence which can weaken the dosage of radiation under the secure line.

For a nuclear reactor, we should have some primary components which include the fuel material, structural materials, moderators, coolants, and finally the control, shielding, and safety materials. These materials should have specific properties which can be classified into two categories. Firstly, the general properties include structural, elastic, and mechanical properties along with reproducibility. The second one is the unique properties like radioactivity. Regardless of the fuel materials which must have unique properties, the different components of the reactor need a different kind of properties. The structural materials are aiding the exchange of the power between the core and the external system. These materials should have the properties like high melting point, high strength to weight ratio, good thermal stability, good corrosion resistance, high thermal neutron scattering, low vapor pressure, deficient thermal neutron absorption, etc. The moderators and reflectors are sharing the same set of properties which include high neutron scattering cross section, a large energy loss by a neutron per collision, and a low neutron absorption cross section. The high neutron scattering cross section of the moderators and reflectors helps to reduce the neutron leakage and escape. The properties of the blanket materials in a fast reactor are quite different from those for moderators and reflectors in a thermal reactor. The blanket materials should have a high neutron 
absorption cross section. In addition to the nuclear requirements, these materials should be cost-effective, corrosion resistance, non-toxic, and ductile $[4,5]$.

Theoretically, a material with a critical density can decrease the radiation intensity, which makes them a shielding material. But based on the magnitude of energy, type of radiation, and the risk of exposure, shielding materials should be decided in advance. The conventional way of shielding the hazardous radiations involves building profound thick concrete barriers and using lead plates. Many scientists tried to improve the radiation protection efficiency of these concretes by mixing with minerals or changing the grain size [6, 7]. Similarly, the evaluation of radiation protection capacity of several alloys composites and polymers is also on the run [8-10]. In any case, these materials and techniques have downsides. For instance, these materials are not see through. Concrete walls are inclined to have cracks; once fixed, we can almost consider it as immobile, and the constituents can be different in a different part. Additionally, the world could be a better place if we reduce the usage of poisonous materials like lead $(\mathrm{Pb})$. Like in any other industry, the nuclear industry also realized the potential applications of the glasses. Glasses have several advantages, and it has been a part of our culture for thousands of years. They can be used as a shielding material as well as storage for the nuclear wastes. Glasses are comfortable with making, clean, and transport. It can be tested for the impact of different constituents. It has corrosion resistance, could be cost-effective and transparent, which is a unique characteristic. The different factors of glass, such as the formers, modifiers, and intermediates, could be different according to their purposes [11-20]. The competence of glass to prevent hazardous radiation is inextricably linked with its composition. It should contain heavy-metal oxide (heavy-MO) in ample concentrations to stabilize the shielding properties with optical and mechanical properties. It is a prerequisite consideration in the glass making. Likewise, for the sensible handling of the hazardous rays, it is necessary to know the photon interaction parameters (PIP) like mass attenuation coefficient (MAC), half-value thickness $\left(\Delta_{0.5}\right.$, or HVL), transmission factor (TF), and radiation protection efficiency (RPE) [18].

Among the different glass formers, borates have some unique properties. It has a considerable low melting temperature, high transparency, and the highest glass-forming affinity which does not crystallize even with slow cooling. The borate glasses are not an optimal candidate for $\gamma$ radiation shielding $(\gamma-\mathrm{RS})$ or other protective purposes in its pure form owing to its low chemical durability due to high water affinity. Hence for practical purposes, the metal oxides like $\mathrm{SiO}_{2}, \mathrm{TeO}_{2}, \mathrm{PbO}, \mathrm{BaO}, \mathrm{ZnO}, \mathrm{Bi}_{2} \mathrm{O}_{3}$, etc., will add to the borate according to the purposes [17]. $\mathrm{ZnO}$ is an excellent candidate for giving stability for the borate glasses at a low cost. Also, the non-poisonous nature makes it an eco-friendly ingredient. Excess non-bridging oxygen (non-BO) formation causes when $\mathrm{ZnO}$ breaks the $\mathrm{BO}_{4}$ units with the capacity of a network modifier [14, 16, 21]. Glasses having barium are an excellent preference for radioactive liquid waste disposal owing to its sulfate abiding capacity. It can be used as a barrier in plasma display ribs and as a $\gamma-\operatorname{RS}$ material $[12,16,18,19]$. Both barium and zinc can be lowering the glass-forming temperature of the borates, even without a cluster formation [11]. $\mathrm{Bi}^{3+}$ is a massive, stable, and nonradiative nucleus. Owing to the lower field strength of $\mathrm{Bi}^{3+}, \mathrm{Bi}_{2} \mathrm{O}_{3}$ can act as a conditional network former. Bismuth borate glasses have a relatively large thermal expansion coefficient, low optical dispersions, and low glass transition temperatures.

Recently, various binary, ternary, and poly borate glasses are evaluated for their structural and $\gamma$-RS properties. M. Rashad et al. [12] analyzed the PIP values and optical properties of barium lithium borate glasses. M.G.Dong et al. [20] employed simulation techniques to evaluate the change in different PIP of various glass systems, formed by silicates, tellurites, and borates, with germanate as the modifier. I. Boukhris et al. [13] and M.H.A. Mhareb et al. 
[16] worked on zincborate glasses for the $\gamma$-RS characteristics. And G. Lakshminarayana et al. [15] dealt with the impact of bismuth oxide in $\gamma-\mathrm{RS}$ characteristics of the binary and ternary glasses employing the theoretical and computational approaches. Based on the above facts and figures, it is acceptable to investigate the glasses for radiation protection. And also, the essential properties of the glasses like optical transparency, stress and breakage strength, heat resistance, and chemical durability are expected for the selected composition from the literature review. Hence, it is sensible and worthy of the investigation of a series of barium-zincborate through a four-phase analysis (physical, structural, elastic, and $\gamma-\mathrm{RS}$ ) by varying the concentration of bismuth oxide.

\section{Materials and methods}

\subsection{Synthesis of $\mathrm{Bi}^{3+}$ varying barium-zincborate glasses}

A faction of bismuth barium-zincborate (BZX) glasses is fabricated by the melt-quenching technique using analytical grade, $99.99 \%$ pure chemicals supplied by Sigma-Aldrich $\left(\mathrm{B}_{2} \mathrm{O}_{3}\right.$, $\mathrm{ZnO}, \mathrm{BaCO}_{3}, \mathrm{Bi}_{2} \mathrm{O}_{3}$, and $\mathrm{Dy}_{2} \mathrm{O}_{3}$ ) [22]. In the present study, about $15 \mathrm{gm}$ batches of chosen composition were weighed up and thoroughly ground using the agate mortar. This mixture is then made to melt in an electric furnace at $1025^{\circ} \mathrm{C}$ for $55 \mathrm{~min}$. During melting, the crucible containing mixture should be stirred two or three times to obtain homogeneity. Keep the brass mold preheated, and the molten mixture is poured into it and afterward by annealing at $350{ }^{\circ} \mathrm{C}$ for $12 \mathrm{~h}$, for removing the thermal strain and bubbles and for improving the mechanical strength. The obtained glasses were polished to achieve plane surface, which will help to get better optical measurements. The chemical compositions (in wt $\%$ ) used for the preparation of BZX glasses and the corresponding glass codes are given in Table 1. The glasses are coded BZ00-BZ30 depending on their $\mathrm{Bi}_{2} \mathrm{O}_{3}$ content in weight percentage. The $\mathrm{BaCO}_{3}, \mathrm{ZnO}$, and $\mathrm{Dy}_{2} \mathrm{O}_{3}$ content in the glasses remains the same for all the samples. The densities of the glasses have been calculated using the Archimedes principle, in which xylene is an immersion liquid. The refractive index estimation is done by Abbe's refractometer with mono-bromonaphthalene as the contact liquid, at $589.3 \mathrm{~nm}$. For obtaining XRD and FTIR spectra, the authors employed similar types of equipment reported in Ref. [22] and performed at room temperature only.

\subsection{Radiation-shielding characteristics}

The standard way to determine the radiation-shielding ability of these glass samples is to conduct an experimental study calculating various parameters. However, due to the COVID-19 pandemic, laboratories are currently closed for operation. To circumvent this inconvenience while continuing to carry out investigations, simulations are used as an alternative method for experiments. Monte Carlo N-Particle Transport (MCNP) code is a commonly used simulation to determine the linear (LAC) and mass attenuation coefficient (MAC) of a sample based on the prediction of the average tack length (ATL) of gamma-photons in its pathway inside the glass sample. MCNP code was used to evaluate the gamma-photons' track length inside the fabricated glass samples. To achieve the required simulation, an input file was arranged. The mentioned input file contains a detailed description of the attenuator material, detector, and gamma-source, as shown in Fig. 1. A gamma-ray source emits photons with energies varied between 0.248 and $1.406 \mathrm{MeV}$ along the $\mathrm{Z}$ direction in the present work. The radioactive source was placed in the center of the arranged geometry and $15 \mathrm{~cm}$ far from 


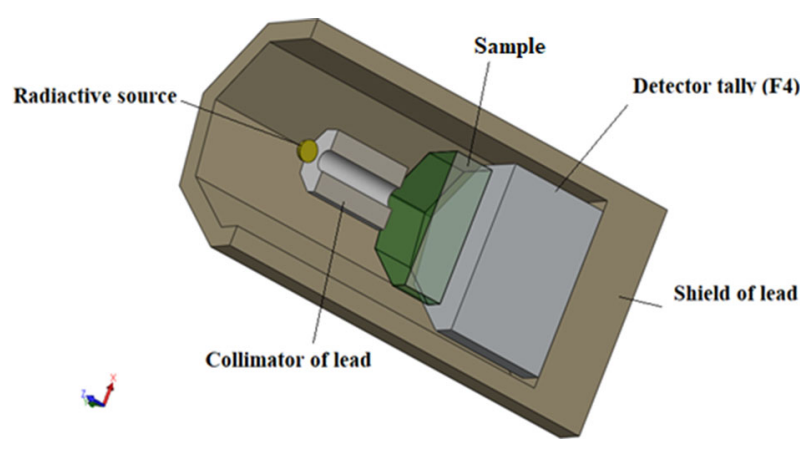

Fig. 1 The geometry and simulation setup

the fabricated glass sample. The emitted photons were collimated using a collimator of lead with a slit $1 \mathrm{~cm}$ in diameter. The collimator diameter $7 \mathrm{~cm}$ and height $10 \mathrm{~cm}$. the collimated photons incident on the glass sample. The chemical composition and density of the fabricated glasses are illustrated in Table 1. According to the input file, the glass samples were in the form of a cylinder with a diameter of $2 \mathrm{~cm}$ and different thicknesses. After the interaction between the incident photons and the fabricated glass, the transmitted photons incident on the detector. The detector and the sample were in contact without any separating distance. The detector was assumed to be F4 tally, to record the track length of the incident photons per unit cell of the detector. The geometry was shielded from the surrounded environment by $5 \mathrm{~cm}$ of lead. The importance card was set up to be 1 for the cells inside the geometry and 0 for cells outside the geometry. Also, the NPS card was set up to stop the interaction after $10^{6}$ histories. Continuous-energy nuclear and atomic data libraries support the MCNP code. The primary cross-sectional data sources for the MCNP-5 nuclear database are ENDF, ACTI, ENDL, ACTI, and T-16 files [23].

Moreover, the predicted ATL was used to calculate the critical shielding parameters such as half-value thickness $\left(\Delta_{0.5}\right)$, transmission factor $(\mathrm{TF})$, and radiation protection efficiency (RPE) according to the following relations [24].

$$
\begin{gathered}
\mathrm{LAC}=\frac{1}{x} \ln \left(\frac{I}{I_{o}}\right) \\
\mathrm{LAC}=(\mathrm{MAC}) * \rho \\
\Delta_{0.5}=\frac{\ln (2)}{\mathrm{LAC}} \\
\mathrm{TR}(\%)=e^{-\mathrm{LAC}} \\
\operatorname{RPE}(\%)=\left(1-e^{-\mathrm{LAC}}\right) * 100
\end{gathered}
$$

where $w_{i}$ and $(\mathrm{MAC})_{i}$ define the fractional weight and the mass attenuation coefficient of constituting elements, respectively. 


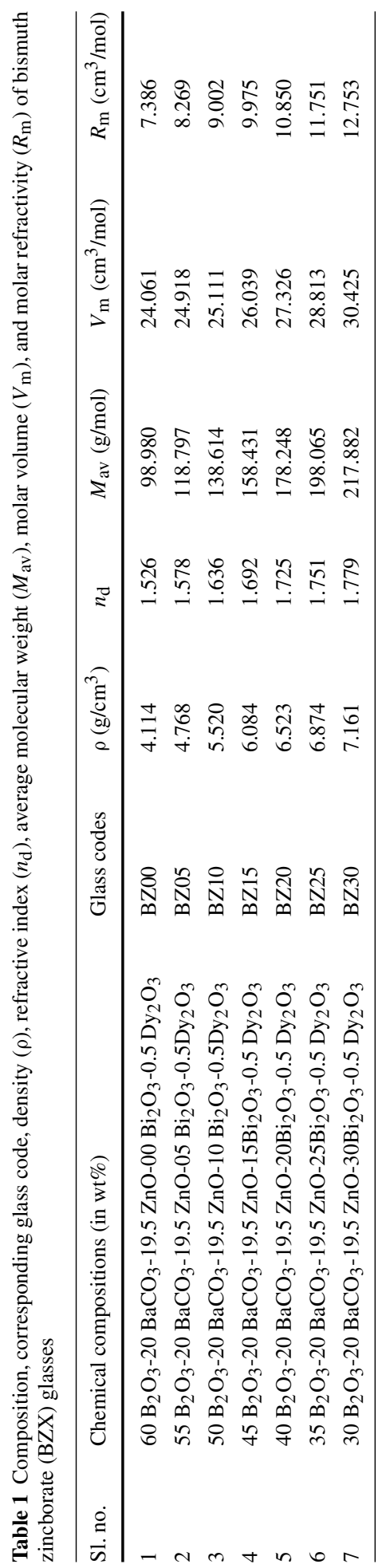




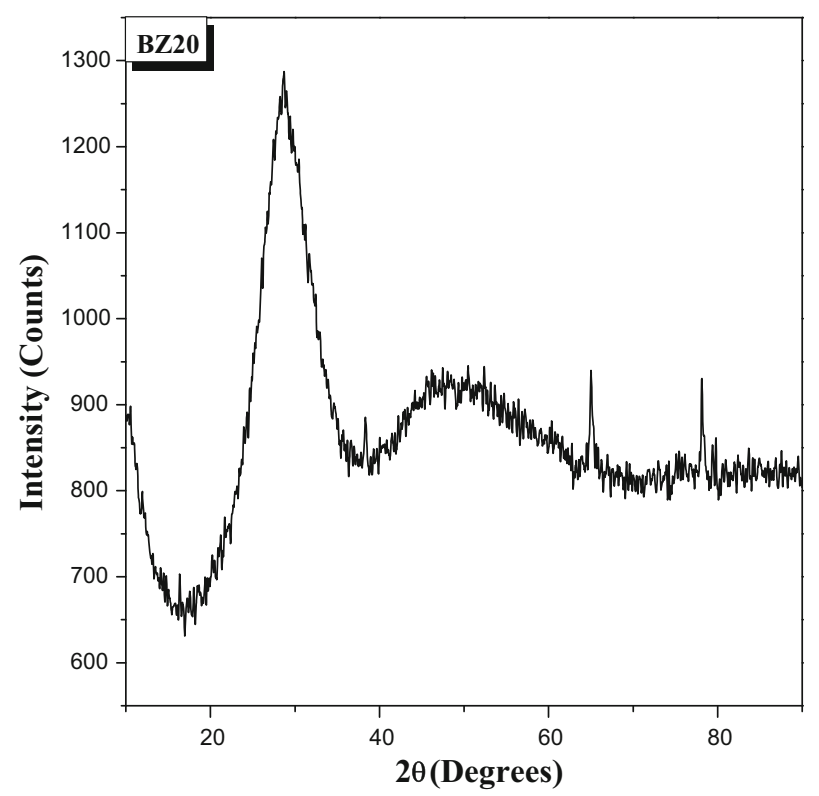

Fig. 2 XRD pattern of the $20 \mathrm{wt} \% \mathrm{Bi}_{2} \mathrm{O}_{3}$ contain barium-zincborate glass

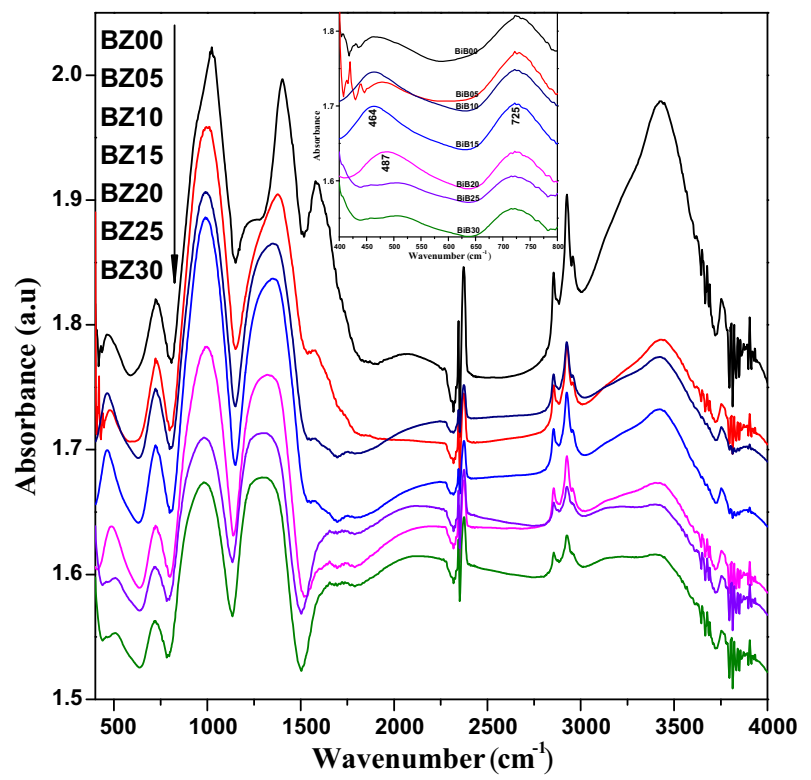

Fig. 3 Infrared absorbance spectra of the BZX glass 


\section{Results and discussions}

\subsection{Physical properties}

The physical properties of the BZX glasses are evaluated following the previous work [22] and displayed in Table 1. The density $(\rho)$ of the BZX glasses shows an augmentation. As the $\mathrm{Bi}_{2} \mathrm{O}_{3}$ amount is increased, the oxide replaces the lighter $\mathrm{B}_{2} \mathrm{O}_{3}$ present, which is increasing the glass density. The glass samples are arranged in the order of increasing density. From BZ00, having a density of $4.114 \mathrm{~g} / \mathrm{cm}^{3}$ to BZ30, having a density of $7.161 \mathrm{~g} / \mathrm{cm}^{3}$. The factors like glass structure compactness, geometrical configuration changes, and the interstitial spatial dimensions of the glass and coordination number will affect the density of the glass. The addition of $\mathrm{Bi}_{2} \mathrm{O}_{3}$ into the host matrix will change the tetragonal $\mathrm{BO}_{4}$ groups into the triangular $\mathrm{BO}_{3}$ groups by the formation of non- $\mathrm{BO}$, and when the number of non-BO increases the density of the glass also increases. Similarly, the refractive index $\left(n_{\mathrm{d}}\right)$ also showed an escalated trend, 1.526 to 1.779 , with increasing concentration of $\mathrm{Bi}^{3+}$; seem to be dependent on the increasing number of non-BO. The refractive index and density are found to be linearly proportional, hence increase with an increase in the number of non-BO [22]. The molar volume $\left(V_{\mathrm{m}}\right)$ of the glasses follows the same trend as $\rho$, which might be a sign of the structural changes of the glasses like an increase in the non-BO bond density. Generally, $\mathrm{n}_{\mathrm{d}}$ relies on the composition of the glass as the polarizability of the non-BO is higher than that of bonding ones [11]. An elevated value of molar refractivity $\left(R_{\mathrm{m}}\right)$ with increasing concentration of $\mathrm{Bi}^{3+}$ confirms the creation of non-BO in the glasses. Decreasing metallization $(M)$ and energy-gap $\left(E_{\mathrm{g}}\left[n_{\mathrm{d}}\right]\right)$ values with increasing $\mathrm{Bi}^{3+}$ is a sign of the nonmetallic nature of the BZX glasses $[18,25]$.

$$
M=1-\left(\frac{R_{\mathrm{m}}}{V_{\mathrm{m}}}\right)
$$

\subsection{Structural examination}

The XRD spectrum of the BZ20 glass (Fig. 2) is documented in the range $10^{\circ} \leq \theta \leq 90^{\circ}$. The analyzed sample's amorphous nature is confirmed from the spectrum, as there are no sharp peaks [26]. The existence of nucleation will generate sharp peaks in the spectrum. We can expect the same amorphous nature for the rest of the glasses in the BZX series as the methodology followed is exactly alike at a similar laboratory environment. Figure 3 portrays the FTIR absorbance spectra recorded in the region $400-4000 \mathrm{~cm}^{-1}$ of the BZX samples. The absorption in the lower-energy region is very much essential for the confirmation of metal-oxygen bonds. And the same is portrayed as an enlarged inset image. The band assignments of each peak in the spectra are enlisted in Table 2. The various functional groups presented in a borate glass matrix are $\mathrm{BO}_{3}$ units, $\mathrm{BO}_{4}$ units, boroxyl rings, etc. All these are active in their respective active IR areas [18, 27]. In the low-order glasses, the metal-oxide bonds are presented at $460 \mathrm{~cm}^{-1}$, whereas the bands are shifted toward $490 \mathrm{~cm}^{-1}$ in the higher-order glasses due to the internal structural changes. IR absorption of $\mathrm{CO}_{2}$ is presented at $2370 \mathrm{~cm}^{-1}$ due to the measuring conditions/errors [18]

\subsection{Structural properties}

The structural characteristics of the BZX glasses are evaluated by making use of the expressions used in previous work [18] and given in Table 3. The boron-boron separation $[r(\mathrm{~B}-\mathrm{B})]$ and bismuth-bismuth separation $[r(\mathrm{Bi}-\mathrm{Bi})]$ will provide information about the 


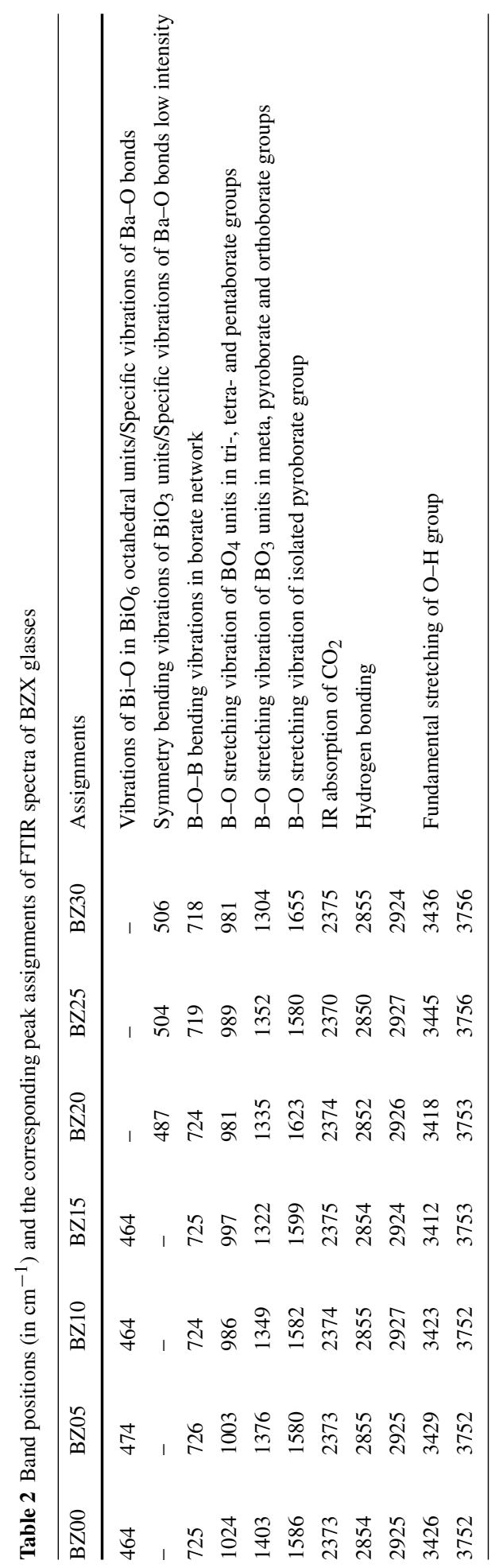




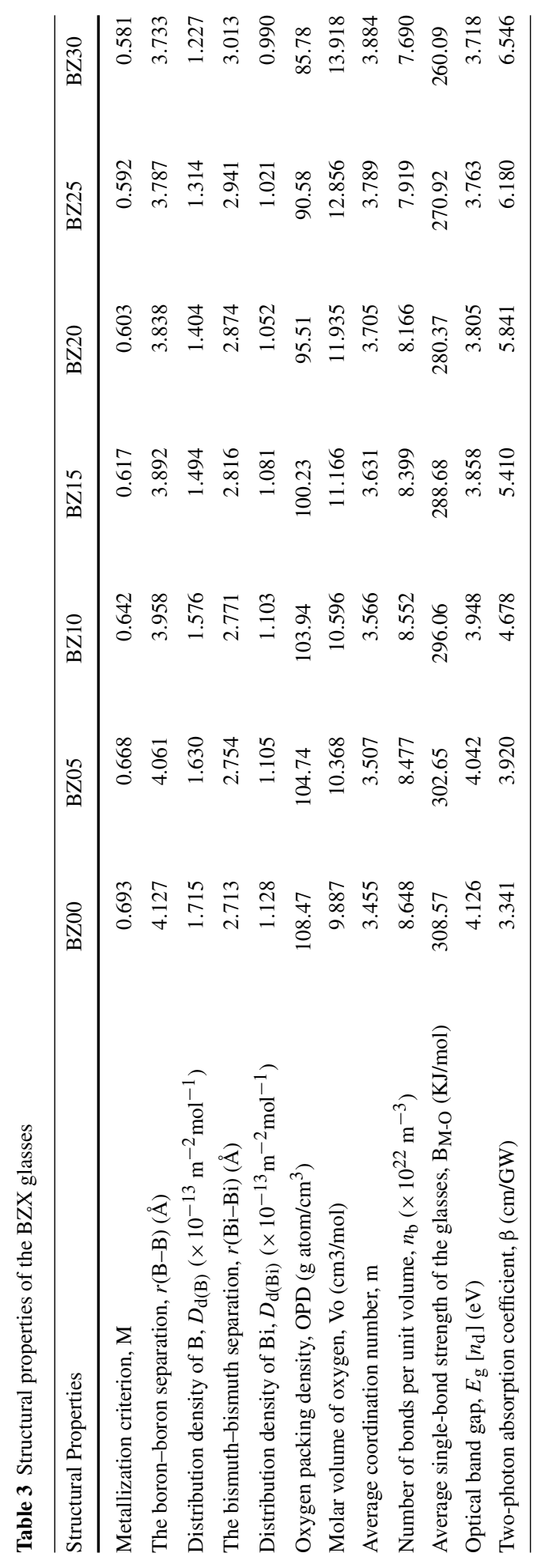


compactness of the glasses. The average values of these separations rely on the molar volumes of boron $(\mathrm{B})\left[V_{\mathrm{m}}^{\mathrm{B}}\right]$ and bismuth $(\mathrm{Bi})\left[V_{\mathrm{m}}^{\mathrm{Bi}}\right]$ which are strongly interconnected to their ionic radii.

$$
\begin{gathered}
r(\mathrm{~B}-\mathrm{B})=\left(\frac{V_{\mathrm{m}}^{\mathrm{B}}}{N_{\mathrm{A}}}\right)^{1 / 3} \\
r(\mathrm{Bi}-\mathrm{Bi})=\left(\frac{V_{\mathrm{m}}^{\mathrm{Bi}}}{N_{\mathrm{A}}}\right)^{1 / 3} \\
V_{\mathrm{m}}^{\mathrm{B}}=\frac{V_{\mathrm{m}}}{2\left(1-X_{\mathrm{B}}\right)} \\
V_{\mathrm{m}}^{\mathrm{Bi}}=\frac{V_{\mathrm{m}}}{2\left(1-X_{\mathrm{Bi}}\right)}
\end{gathered}
$$

where $X_{\mathrm{B}}$ and $X_{\mathrm{Bi}}$ are the molar fractions of boron and bismuth, respectively, and $N_{\mathrm{A}}$ is the Avogadro number. The $r(\mathrm{~B}-\mathrm{B})$ values decrease with increase in concentration of $\mathrm{Bi}^{3+}$ due to the insertion of $\mathrm{Bi}^{3+}$ into the network, which has a larger ionic radius. On the other hand, the $r(\mathrm{Bi}-\mathrm{Bi})$ values are increasing as the $\mathrm{Bi}^{3+}$ goes higher, owing to a higher $V_{\mathrm{m}}$. Hence, the compactness of the glass matrix can only be deep-rooted by the analysis of the distribution density $\left(D_{\mathrm{d}}\right)$. The $D_{\mathrm{d}}$ of a species is the ratio of the separation between the same to the molar volume of the glass.

$$
\begin{aligned}
D_{\mathrm{d}(\mathrm{B})} & =\frac{r(\mathrm{~B}-\mathrm{B})}{V_{\mathrm{m}}} \\
D_{\mathrm{d}(\mathrm{Bi})} & =\frac{r(\mathrm{Bi}-\mathrm{Bi})}{V_{\mathrm{m}}}
\end{aligned}
$$

The $D_{\mathrm{d}}$ of both $\mathrm{B}$ and $\mathrm{Bi}$ shows a descending trend even with higher $\mathrm{Bi}^{3+}$ concentration which shows the increasing compactness of the higher-order glasses. Figure 4 illustrates the deviation of $D_{\mathrm{d}}$ with the $\mathrm{Bi}^{3+}$ concentration. The oxygen packing density (OPD) and the molar volume of oxygen $\left(V_{\mathrm{o}}\right)$ are in the reverse tendency.

$$
\begin{gathered}
\mathrm{OPD}=\frac{\rho_{\text {glass }} * N_{\mathrm{A}} * \text { Number of oxygen }}{M_{\mathrm{av}}} \\
V_{\mathrm{O}}=\frac{V_{\mathrm{m}}}{\sum_{i}\left(x n_{\mathrm{o}}\right)_{i}}
\end{gathered}
$$

where $x_{i}$ is the molar fraction of each component $i$, and $n_{\mathrm{o}}$ is the number of oxygen atoms in each constituent oxide.

The OPD is dropping off with higher $\mathrm{Bi}^{3+}$ concentration, while the $V_{\mathrm{o}}$ has a substantial growth, and Fig. 5 gives the graphical demonstration. The above two statements simultaneously are pointing out an increase in non-BO. The bond density $\left(n_{\mathrm{b}}\right)$ of any matrix will be altered by incorporating a heavy-metal ion like $\mathrm{Bi}^{3+}$. And $\mathrm{n}_{\mathrm{b}}$ showing a negative trend with the $\mathrm{Bi}^{3+}$ concentration.

$$
n_{\mathrm{b}}=\frac{N_{\mathrm{A}}}{V_{\mathrm{m}}} \sum_{i}\left(x n_{\mathrm{c}}\right)_{i}=\frac{N_{\mathrm{A}}}{V_{\mathrm{m}}} \mathrm{m}
$$

where $m$ is the average coordination number, and $n_{\mathrm{c}}$ is the coordination number of the cation.

Hence, the augmentation in the $V_{\mathrm{m}}$ might be because of the structural changes in the network. Increased $\mathrm{B}-\mathrm{O}$ vibrations might be the outcome of increased $\mathrm{Bi}^{3+}$ concentration. The average coordination number $(\mathrm{m})$ can give us the metal-oxygen bond nature. And an increase in trend of ' $\mathrm{m}$ ' with $\mathrm{Bi}^{3+}$ concentration proves the additional formation of non-BO 


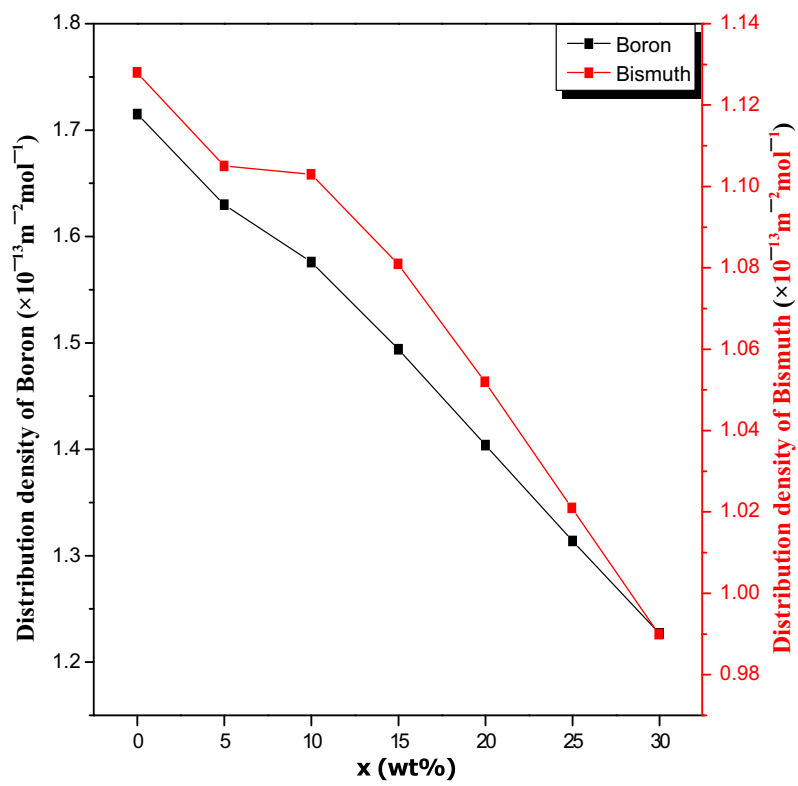

Fig. 4 Composition dependence of distribution densities of boron and bismuth of BZX glasses with respect to $\mathrm{Bi}_{2} \mathrm{O}_{3}$ concentration

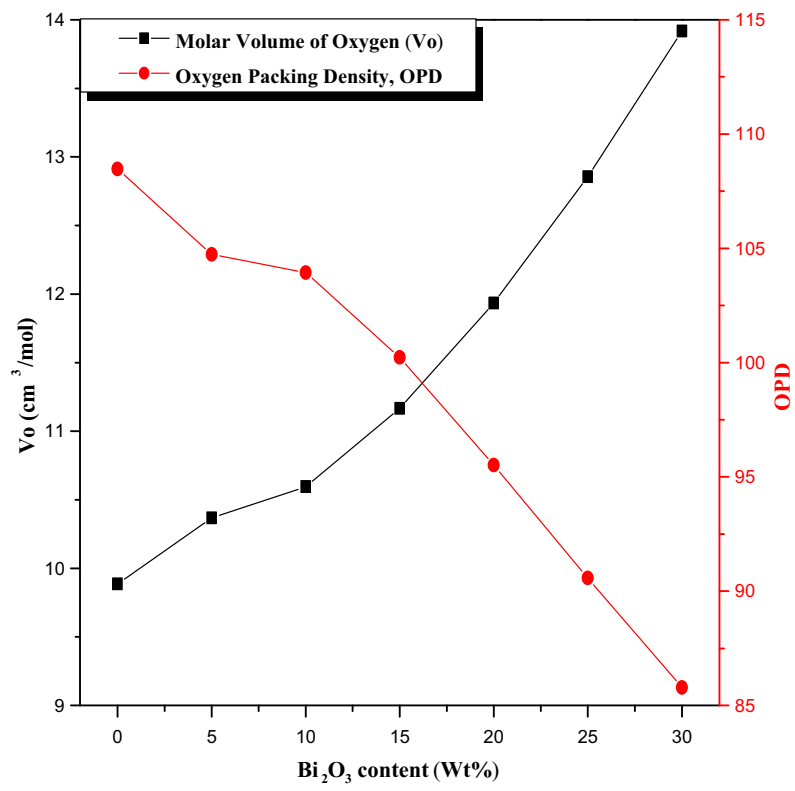

Fig. 5 The composition-dependent variation of the molar volume oxygen $\left(V_{\mathrm{o}}\right)$ and the oxygen packing density (OPD) of BZX glasses with increasing concentration of $\mathrm{Bi}_{2} \mathrm{O}_{3}$

and hence the existence of $\mathrm{BO}_{4}$ units in the glass matrix. All the above results establish an enhanced cross-linking of the glass matrix with increasing concentration of $\mathrm{Bi}^{3+}$ [28]. The 
average single-bond strength of the glasses $\left(\mathrm{B}_{\mathrm{M}-\mathrm{O}}\right)$ shows a demoted trend with the $\mathrm{Bi}^{3+}$ concentration. This might be the outcome of the formation of $\mathrm{Bi}-\mathrm{O}-\mathrm{Bi}$ units which have a higher ionicity [29]. The same is confirmed by the FTIR spectra of the BZX glasses. The two-photon-absorption coefficient (2PAC) can be estimated using the optical band gap. And a low-order 2PAC value makes the BZX glasses useful for the nonlinear optical applications [30].

$$
\beta(\mathrm{cm} / \mathrm{GW})=36.66-8.1 \times E_{\mathrm{g}}(\mathrm{eV})
$$

\subsection{Elastic properties}

The pure borate network is laminar shaped, which consists of trigonal-planar borate units. Any addition that caused the breakage of trigonal-planar units to the tetrahedral borate units will create the non-BO, which helps to increase the connectivity of the glass matrix. Hence, the incorporation of $\mathrm{Bi}^{3+}$ into the glass matrix causes the breakage of $\mathrm{B}-\mathrm{O}-\mathrm{B}$, which confirms the elevated $V_{\mathrm{m}}$. Also, with the capacity of a network modifier, the addition of $\mathrm{Bi}^{3+}$ ended up in the formation of $\mathrm{Bi}-\mathrm{O}-\mathrm{Bi}$ bonds. It will increase the chemical durability and the thermal stability of BZX glasses. More $\mathrm{Bi}-\mathrm{O}-\mathrm{Bi}$ units will be introduced while increasing the $\mathrm{Bi}^{3+}$ concentration, which will alter the cross-link density $\left(\mathrm{E}_{\mathrm{d}}\right)$ and thus condense the structure [31].

Various elastic moduli ( $\left.M_{\text {elastic }}\right)$ and the Poisson's ratio ( $\left.\mu_{\text {cal }}\right)$ of the BZX glasses evaluated using the Makishima and Mackenzie model $[32,33]$ and enlisted in Table 4. The estimation is based on the packing density $\left(C_{\mathrm{g}}\right)$ of the composition as well as the bond dissociation energy (BDE) of the corresponding constituents. Obviously, there will be a change in the $M_{\text {elastic }}$ associated with a material phase change. The estimation of $M_{\text {elastic }}$ can provide information about the glass structure as they very much rely on nature and interatomic interactions of the chemical bond. Young's modulus $\left(E_{\mathrm{t}}\right)$ depends on the bond's nature, whereas the bulk modulus $\left(K_{\mathrm{t}}\right)$ measures the changes in the stretching force constant of the bond and $\succeq_{\mathrm{d}}$. From the mathematical expressions [31-39], it is evident that the $M_{\text {elastic }}$ increases with an increase in the velocity or density. For BZX glasses, even though there is an increase in the density, $M_{\text {elastic }}$ shows a converse trend. Hence for the BZX glasses, the network bond type has a crucial role in determining the $M_{\text {elastic }}$. The $M_{\text {elastic }}$, especially $E_{\mathrm{t}}$ is directly proportional to the $C_{\mathrm{g}}$. With a demoted $C_{\mathrm{g}}$, we can expect the reverse trend of $M_{\text {elastic }}$ with the $V_{\mathrm{m}}$. Also, the $C_{\mathrm{g}}$ is in an inverse relation with $V_{\mathrm{m}}$, and this also might be the reason for the reverse trend of $M_{\text {elastic }}$ [36]. The variation of theoretically calculated $M_{\text {elastic }}$ with $V_{\mathrm{m}}$ is graphically demonstrated in Fig. 6 . The resistance provided by a material toward any permanent deformation or penetration refers to the microhardness $\left(H_{\mathrm{m}}\right)$. The variation in $H_{\mathrm{m}}$ is negligible for the BZX glasses.

The network compactness can be measured using another vital parameter known as atomic packing fraction $\left(A_{\mathrm{PF}}\right) . A_{\mathrm{PF}}$ is the ratio of the volume summation of atoms to the $V_{\mathrm{m}}$. Even though the variation in the $A_{\mathrm{PF}}$ is nominal, the increase in trend is being reversed after BZ15. It could be because of the elevation in the fraction of tetrahedral borate units up to $x=15$, which has a larger packing density. When the value of $\mathrm{x}$ goes further, there might be a creation of non-BO due to the structural change of borate units [40]. Acoustic impedance $(Z)$ is a valuable property for portraying impacts that happen when the sound wave meets the boundary between two media. There is a certain likeness among the reflection 
Table 4 Elastic properties of the BZX glasses

\begin{tabular}{llllllll}
\hline Elastic Properties & BZ00 & BZ05 & BZ10 & BZ15 & BZ20 & BZ25 & BZ30 \\
\hline Poisson's ratio, $\mu_{\text {cal }}$ & 0.2032 & 0.2035 & 0.2039 & 0.2043 & 0.2047 & 0.2052 & 0.2058 \\
Atomic packing fraction, $A_{\mathrm{PF}}$ & 0.8772 & 0.9597 & 1.0430 & 1.0768 & 1.0741 & 1.0496 & 1.0054 \\
Atomic packing density, $\mathrm{Cg}\left(10^{-6} \mathrm{~m}^{-3}\right)$ & 0.736 & 0.706 & 0.696 & 0.665 & 0.628 & 0.589 & 0.551 \\
Acoustic impedance, $\mathrm{Z}\left(10^{5} \mathrm{~g} \mathrm{~cm}^{-2} \mathrm{~s}^{-1}\right)$ & 12.2 & 12.76 & 13.49 & 13.7 & 13.61 & 13.33 & 12.92 \\
Young's modulus, $E_{\mathrm{t}}(\mathrm{GPa})$ & 36.21 & 34.14 & 32.98 & 30.85 & 28.38 & 25.84 & 23.32 \\
Bulk modulus, $K_{\mathrm{t}}(\mathrm{GPa})$ & 31.88 & 28.84 & 27.44 & 24.55 & 21.32 & 18.21 & 15.37 \\
Shear modulus, $S_{\mathrm{t}}(\mathrm{GPa})$ & 14.70 & 13.95 & 13.51 & 12.73 & 11.83 & 10.90 & 9.98 \\
Longitudinal modulus, $L_{\mathrm{t}}(\mathrm{GPa})$ & 51.47 & 47.43 & 45.45 & 41.52 & 37.09 & 32.75 & 28.67 \\
Microhardness, $H_{\mathrm{m}}(\mathrm{GPa})$ & 1.737 & 1.718 & 1.688 & 1.663 & 1.636 & 1.606 & 1.570 \\
Fractal dimension, $d_{\mathrm{F}}$ & 1.844 & 1.935 & 1.969 & 2.074 & 2.220 & 2.396 & 2.597 \\
The average cross-link density, $\mathrm{七}_{\mathrm{d}}$ & 3.602 & 3.581 & 3.557 & 3.531 & 3.501 & 3.467 & 3.428 \\
Average stretching force constant, $\dot{F}_{\mathrm{s}}(\mathrm{N} / \mathrm{m})$ & 506 & 493 & 479 & 464 & 447 & 427 & 406 \\
\hline
\end{tabular}

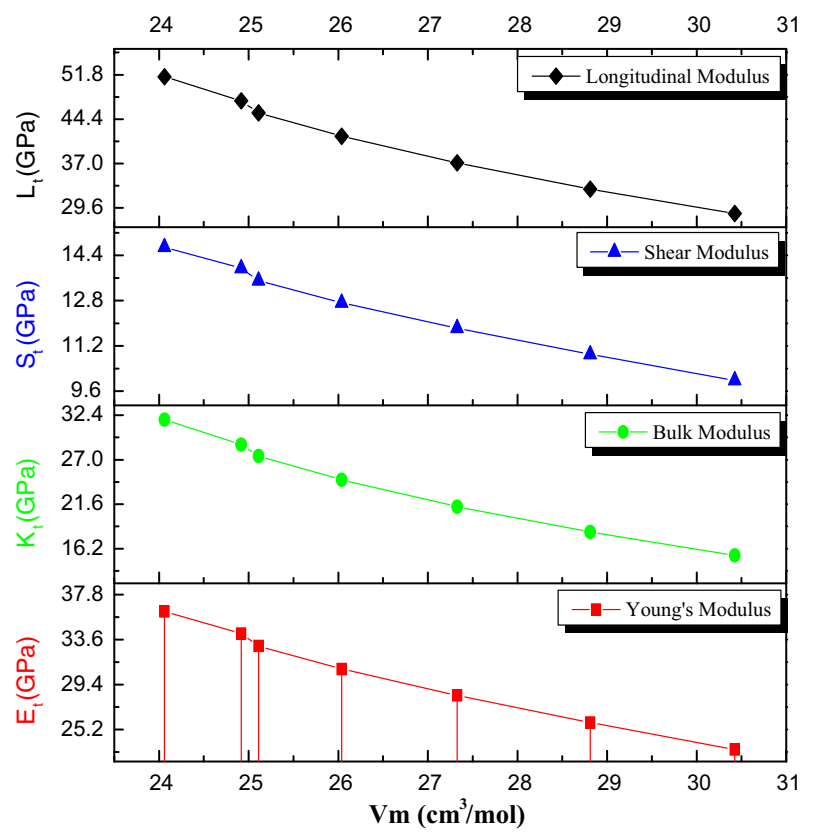

Fig. 6 The elastic moduli of the BZX glasses as a function of the molar volume $\left(V_{\mathrm{m}}\right)$ of the glasses

and transmission of longitudinal ultrasound and light through the phase boundaries. The transmitted intensity of the sound is related to $Z$ as the following equation,

$$
\frac{I_{\text {transmitted }}}{I_{\text {incident }}} \cong\left[\frac{Z_{\text {air }}}{Z_{\text {glass }}}\right]^{2}\left[\frac{v_{\text {sound in glass }}}{\pi f d_{\text {glass }}}\right]^{2}
$$

where $d$ is the glass thickness and $f$ is the frequency. The larger the $Z$, the smaller the intensity transmitted. Like the $A_{\mathrm{PF}}, Z$ is also showing an increase in trend up to the BZ15. 


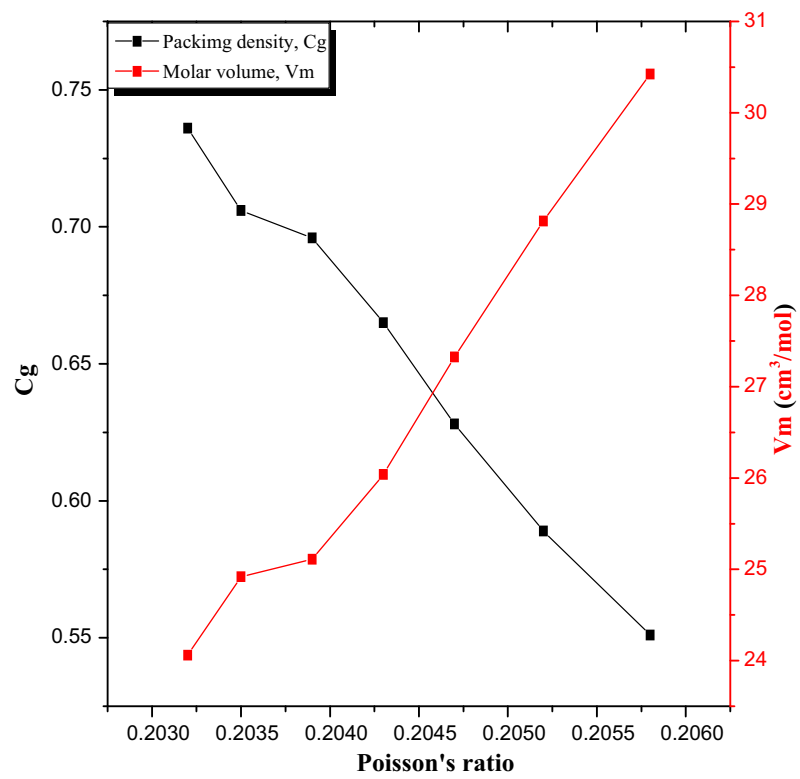

Fig. 7 The Poisson's ratio as a function of packing density $\left(C_{\mathrm{g}}\right)$ and the molar volume $\left(V_{\mathrm{m}}\right)$ of the BZX glasses

When a perpendicular tensile force is applied, the glass will experience a lateral-strain. And it will be maximum in the absence of bridging oxygen (BO). The more BO, which makes the network more cross-linking, the lateral strain will be minimized. The measure of this transversal enhancement concerning the axial compression is known as the Poisson's ratio $\left(\mu_{\mathrm{cal}}\right)$. Taking up the $C_{\mathrm{g}}$ of the BZX glasses, $\mu_{\mathrm{cal}}$ evaluated, and the relatively lesser values prove a high cross-linking density [41]. The graphical illustration of the dependence of $\mu_{\mathrm{cal}}$ with $V_{\mathrm{m}}$ and $C_{\mathrm{g}}$ is portrayed in Fig. 7. The variation in the $\mu_{\mathrm{cal}}$ caused a significant change in dimensionality, which is confirmed by the estimation of the fractal dimension $\left(d_{\mathrm{F}}\right)$. The $d_{\mathrm{F}}$ gives a valuable dimensionality picture of the matrix. For a 3D structure, $d_{\mathrm{F}}$ is 3 and 2 for the 2D network. From the evaluated values of $d_{\mathrm{F}}$, it is evident that the dimensionality of the glass network changes from $2 \mathrm{D}$ to $3 \mathrm{D}$. Hence, the $\mathrm{Bi}^{3+}$ addition makes the glass matrix hard and stress resistant. The average stretching force constant $\left(\dot{F}_{\mathrm{s}}\right)$ showed a gradual reduction which might be owing to an increase in bond length or interatomic spacing.

\subsection{Radiation attenuation characteristics}

The MAC describes the ability for a material to attenuate radiation and is needed to compute other parameters, with a more excellent value signifying a better shield. With MCNP5 simulation, the MAC values of all the samples are various energies were calculated. The simulated MAC values were compared to the XCOM's values to determine the simulation process's accuracy. The theoretical values were obtained from the XCOM database [42]. The two methods are compared in Table 5. The two received values can be observed to be very close together for all seven glasses at all energies within an acceptable deviation. For instance, at $0.248 \mathrm{MeV}$, the BZ00 glass has a MAC equal to $0.1373 \mathrm{~cm}^{2} \mathrm{~g}^{-1}$ according to MCNP5, and a MAC of $0.1374 \mathrm{~cm}^{2} \mathrm{~g}^{-1}$, according to XCOM. For the BZ30 glass at $1.406 \mathrm{MeV}$, its 


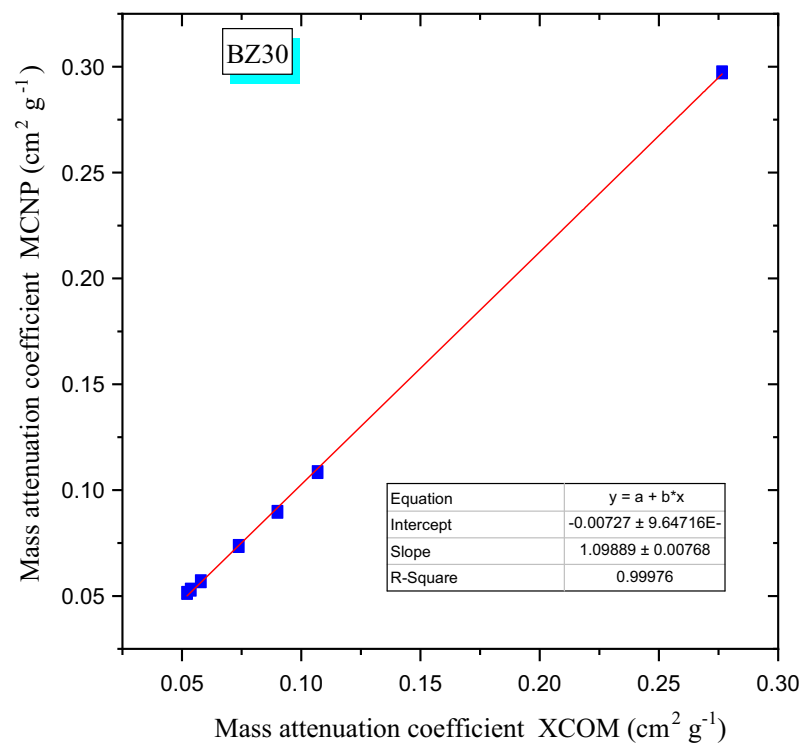

Fig. 8 Comparison between the simulated and calculated MAC

MACs are equal to 0.0514 and $0.521 \mathrm{~cm}^{2} \mathrm{~g}^{-1}$ based on MCNP5 and XCOM, respectively. The table accounts for differences in energies and composition of the glasses, and neither caused inaccuracies in the simulation. Finally, the correlation between the two values is determined in Fig. 8. When plotting and comparing the MAC values from both methods, the R-squared value was calculated to be practically one, which signifies that the methods agree with each other almost exactly. Therefore, based on these results, it can be confirmed that the MNCP5 code is an accurate method for determining the radiation-shielding ability of the tested samples.

With the MAC values calculated, other essential parameters were determined to evaluate the glasses further. The first of these is the linear attenuation coefficient or LAC. The LAC is attained by multiplying the MAC by the density of the sample, with the greater value being more desirable. Figure 9 illustrates a three-dimensional model of the LAC against energy and the $\mathrm{Bi}_{2} \mathrm{O}_{3}$ content in weight percentage. The influence of energy on the LAC can first be examined. The figure demonstrates that for all the glasses as energy increases, the LAC decreases. This trend occurs because as photons increase in energy, they can penetrate through the glass with greater ease, decreasing the probability of interaction and decreasing the LAC. This decrease, however, occurs in two phases. The first phase occurs at lower energies, where the LAC decreases sharply as energy increases due to the dominance of the photoelectric effect in this range. For instance, the LAC for BZ00 decreases from $0.5648 \mathrm{~cm}^{-1}$ to $0.3550 \mathrm{~cm}^{-1}$ when the energy increases from $0.248 \mathrm{MeV}$ to $0.511 \mathrm{MeV}$. For BZ25, it decreases from $1.8733 \mathrm{~cm}^{-1}$ to $0.7087 \mathrm{~cm}^{-1}$ within the same energies. As energy increases further, the LAC rate decreases by slow down due to the photoelectric effect becoming less dominant. Instead, Compton scattering begins to become increasingly more prevalent. For example, BZ00 decreases from $0.2163 \mathrm{~cm}^{-1}$ to $0.2103 \mathrm{~cm}^{-1}$ and BZ30 decreases from $0.3793 \mathrm{~cm}^{-1}$ to $0.3683 \mathrm{~cm}^{-1}$ when the energy increases from $1.332 \mathrm{MeV}$ to $1.406 \mathrm{MeV}$.

Next, the influence of the $\mathrm{Bi}_{2} \mathrm{O}_{3}$ content on the LAC is observed in Fig. 9. As the amount of $\mathrm{Bi}_{2} \mathrm{O}_{3}$ increases, the LAC increases with it at all energies. At $0.81 \mathrm{MeV}$, the LAC values 


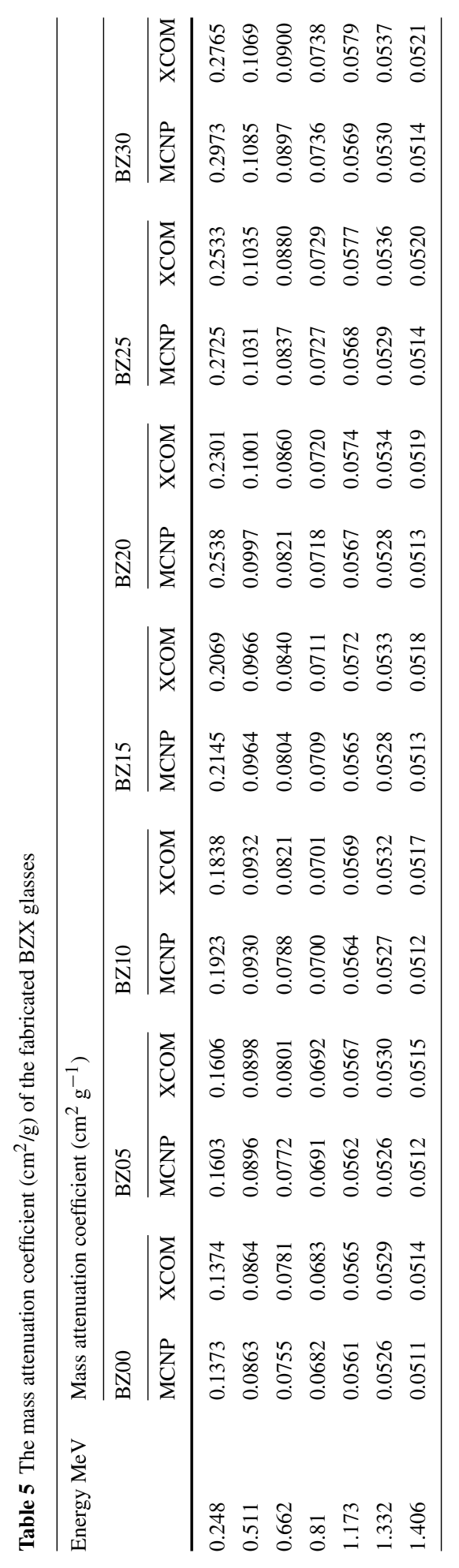




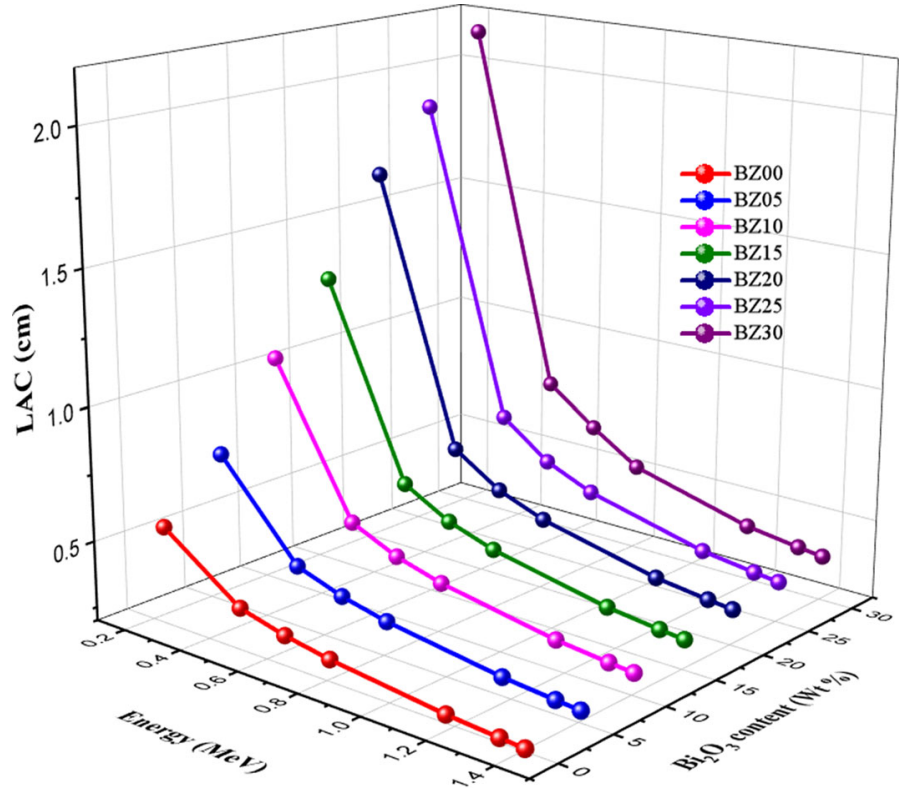

Fig. 9 The linear attenuation coefficient of BZX glasses

are equal to $0.2805,0.3294,0.3863,0.4313,0.4683,0.4996$, and $0.5269 \mathrm{~cm}^{-1}$ for BZ00, BZ05, BZ10, BZ15, BZ20, BZ25, and BZ30, respectively. This increase is caused by an increase in the glass density, as the weight of the $\mathrm{Bi}_{2} \mathrm{O}_{3}$ increases. Therefore, as the $\mathrm{Bi}_{2} \mathrm{O}_{3}$ content in the glasses increases, and the density along with it, the attenuation ability of the glasses increases as well. In can then be concluded that BZ30 is the more effective shield out of the investigated glasses at all the tested energies.

Another important radiation-shielding parameter is called the half-value layer (HVL), representing the thickness of a material required to reduce the intensity of the incoming radiation intensity in half, with a smaller thickness signifying a better shield. Figure 10 plots the HVL against energy and the $\mathrm{Bi}_{2} \mathrm{O}_{3}$ content in a three-dimensional diagram. All the HVL values can be observed to increase as energy increases. This trend occurs because as the energy of the incoming photons increases, the material needs to be thicker to reduce the intensity in half. For the BZ15 glass, the HVL increases from $0.5312 \mathrm{~cm}$ at $0.248 \mathrm{MeV}$, to $1.6072 \mathrm{~cm}$ at $0.81 \mathrm{MeV}$, and $2.2218 \mathrm{~cm}$ at $1.406 \mathrm{MeV}$. In terms of density, as the $\mathrm{Bi}_{2} \mathrm{O}_{3}$ content in the glasses increases, the HVL decreases. At $1.406 \mathrm{MeV}$, the HVL decreases from $3.2957 \mathrm{~cm}$ to $2.2218 \mathrm{~cm}$ to $1.8818 \mathrm{~cm}$ for BZ00, BZ15, and BZ30, respectively. These results indicate that increasing the amount of $\mathrm{Bi}_{2} \mathrm{O}_{3}$ in the glasses, and the density with it, decreases the HVL, increasing the performance of the glasses. Following the LAC, the HVL demonstrates that BZ30 has the best attenuation properties.

Figure 11 illustrates the transmission factor (TF), or transmission rate, of the glasses at three different thicknesses. The transmission factor is the ratio of the photons that passed through the sample to the total photons and is calculated as a percentage. Thicknesses of $0.5 \mathrm{~cm}, 1 \mathrm{~cm}$, and $3 \mathrm{~cm}$ were chosen to evaluate the effect of the material thickness, thinner and thicker samples, on the TF. Four energies were selected, $0.511 \mathrm{MeV}, 0.81 \mathrm{MeV}, 1.173 \mathrm{MeV}$, and $1.406 \mathrm{MeV}$, to understand the effect of low and high energies on the TF. In subfigure [a], the TF for all seven glasses decreases as the material's thickness increases. This trend 


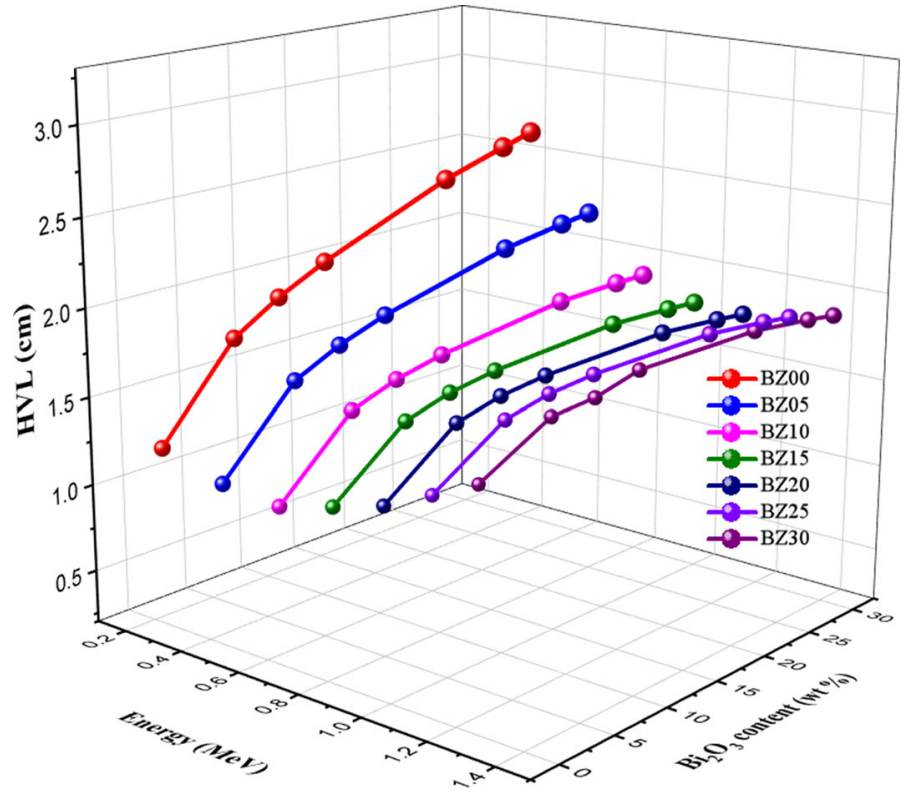

Fig. 10 Variation of the half-value layer versus the incoming photon energy and $\mathrm{Bi}_{2} \mathrm{O}_{3}$ content for the fabricated BZX glasses

occurs because as the thickness of the material increases, less photon can pass through the sample. Thus, the TF decreases for all fabricated samples. At energy $0.511 \mathrm{MeV}$, the TF of the BZ00 glass sample decreases from $83.74 \%$ at a thickness of $0.5 \mathrm{~cm}$, to $70.12 \%$ at $1 \mathrm{~cm}$, and $34.47 \%$ at $3 \mathrm{~cm}$. Besides, it increases with the $\mathrm{Bi}_{2} \mathrm{O}_{3}$ content of the glasses at constant energy and decreases with the thicknesses of the sample. At $0.511 \mathrm{MeV}$ and at a thickness of $1 \mathrm{~cm}$, the TF is equal to $70.12 \%, 65.22 \%, 59.84 \%, 55.64 \%, 52.17 \%, 49.23 \%$, and $45.99 \%$ for BZ00, BZ05, BZ10, BZ15, BZ20, BZ25, and BZ30, respectively. When observing a constant thickness but increasing energy, the TF increases for all seven glasses. For instance, the TF of BZ30 at $3 \mathrm{~cm}$ increases from $9.73 \%$ at $0.511 \mathrm{MeV}$, to $20.58 \%$ at $0.81 \mathrm{MeV}, 29.43 \%$ at $1.173 \mathrm{MeV}$, and $33.21 \%$ at $1.406 \mathrm{MeV}$. This increase occurs because as the energy of the incoming photons increases, more radiation can pass through the material, increasing TF. This figure confirms that BZ30 has better shielding properties out of the investigated glasses.

Additionally, the glasses can perform better at lower energies, and their ability to shield radiation decreases as photon energy increases. Lastly, it can be concluded that the glasses perform significantly better when their thickness increases. Therefore, if space is not a significant concern, a thicker glass should be installed when using these samples.

\section{Conclusion}

The discrepancy of physical, structural, elastic, and radiation-shielding characteristics of a novel bismuth barium-zincborate glasses (BZX) with a chemical formula $(60-x)$ $\mathrm{B}_{2} \mathrm{O}_{3}-20 \mathrm{ZnO}-20 \mathrm{BaCO}_{3}-x \mathrm{Bi}_{2} \mathrm{O}_{3}-0.5 \mathrm{Dy}_{2} \mathrm{O}_{3}(x=0,5,10,15,20,25$, and 30 in wt $\%)$ is analyzed and detailed. BZX series are fabricated using the conventional melt-quenching procedure without any bubbles. While increasing the concentration of $\mathrm{Bi}^{3+}$, there is an aug- 

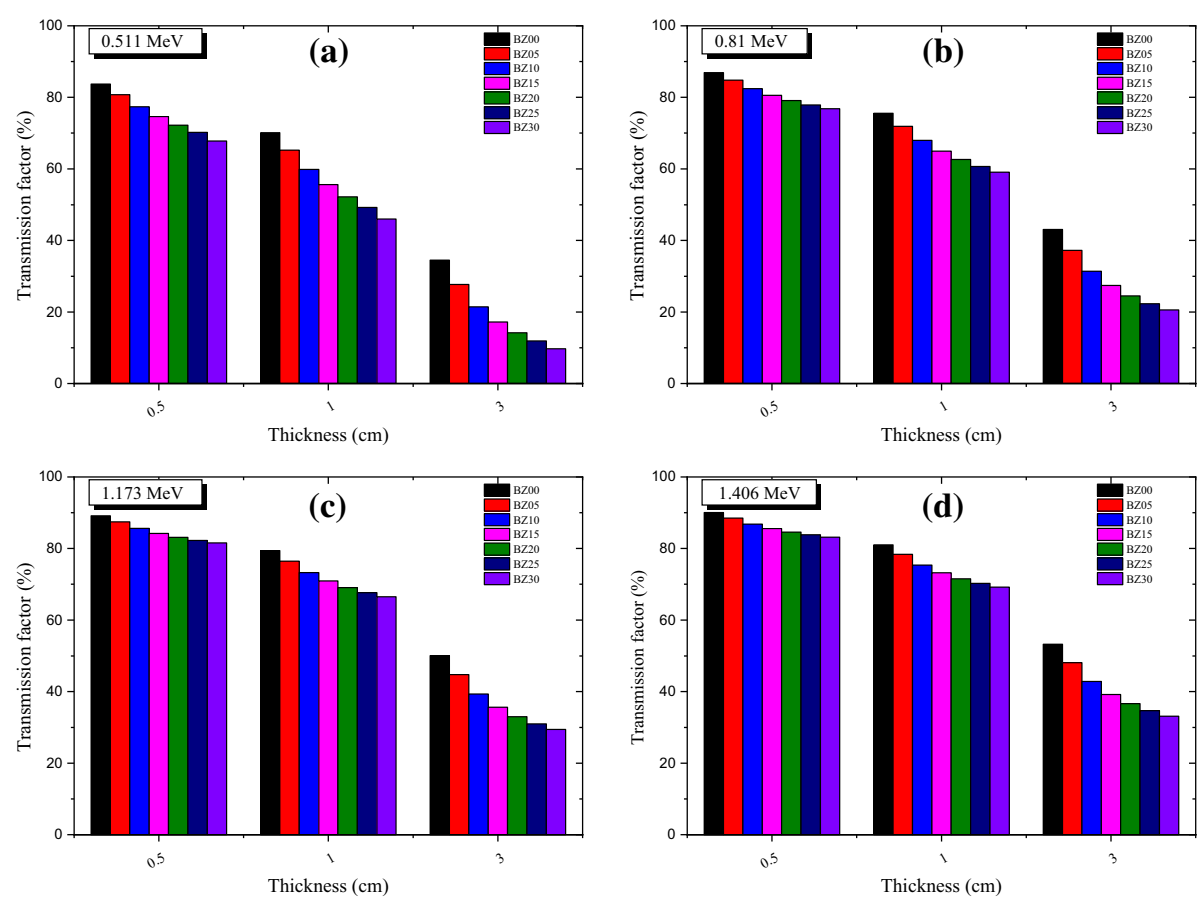

Fig. 11 Variation of the transmission rate versus the glass thickness at various gamma-photon energy

mentation in $\mathrm{BO}_{4}$ units and the metal-oxide bonds, which will enhance the glass stability. So, the bismuth oxide acts as a network former in the present composition. The lowering trend of the average single-bond strength point toward an ionic nature of the BZX glasses and the low-order 2PAC is useful in the perspective of NLO applications.

The elastic moduli and the Poisson's ratio of the present BZX glasses are very much related to the network bond type rather than the density. Hence, downgrading is observed in the elastic moduli. The relatively lesser values prove an elevated cross-linking density. From the evaluated values of fractional dimension, it is obvious that the dimensionality of the glass network changes from 2D to 3D. With the MCNP5 simulation, the MAC values of all the seven samples were calculated to explore the possibility of using the current glasses as shielding materials. The LAC for BZ00 decreases from $0.5648 \mathrm{~cm}^{-1}$ to $0.3550 \mathrm{~cm}^{-1}$ when the energy increases from $0.248 \mathrm{MeV}$ to $0.511 \mathrm{MeV}$ and from $0.2163 \mathrm{~cm}^{-1}$ to $0.2103 \mathrm{~cm}^{-1}$ when the energy increases from $1.332 \mathrm{MeV}$ to $1.406 \mathrm{MeV}$. The HVL results showed that as the energy of the incoming photons increases, the material needs to be thicker to reduce the intensity in half. Also, the HVL results indicate that increasing the amount of $\mathrm{Bi}_{2} \mathrm{O}_{3}$ in the glasses, and the density with it, decreases the HVL, increasing the performance of the glasses. BZX glasses are a better candidate for long-lasting radiation shielding in ventures like the 
medical/industrial purpose PET/X-ray and NPP. The results acquired from the MCNP code are in excellent agreement with those from XCOM.

\section{Compliance with ethical standards}

Conflict of interest We have no conflict of interest to declare.

\section{References}

1. A. Brunnengräber, M. Schreurs, Nuclear Energy and Nuclear Waste Governance Perspectives after the Fukushima Nuclear Disaster, in: Nucl. Waste Gov., Springer Fachmedien Wiesbaden, Wiesbaden (2015), pp. 47-78. https://doi.org/10.1007/978-3-658-08962-7_2

2. L. Parshley, When It Comes to Nuclear Power, Could Smaller Be Better? Yale Sch. Environ. 3, 15 (2020)

3. Application Review Schedule for the NuScale Design, U.S. Nucl. Regul. Comm. (2020). https://www. nrc.gov/reactors/new-reactors/smr/nuscale/review-schedule.html. Accessed 7 Aug 2020

4. B.M. Ma, Nuclear reactor materials and applications, Van Nostrand Reinhold, United States (1983)

5. C.K. Gupta, Materials in Nuclear Energy Applications, vol. II (CRC Press, London, 2018)

6. O. Agar, H.O. Tekin, M.I. Sayyed, M.E. Korkmaz, O. Culfa, C. Ertugay, Experimental investigation of photon attenuation behaviors for concretes including natural perlite mineral. Results Phys. 12, 237-243 (2019). https://doi.org/10.1016/j.rinp.2018.11.053

7. O. Agar, Study on gamma ray shielding performance of concretes doped with natural sepiolite mineral. Radiochim. Acta 106, 1009-1016 (2018). https://doi.org/10.1515/ract-2018-2981

8. O. Agar, M.I. Sayyed, F. Akman, H.O. Tekin, M.R. Kaçal, An extensive investigation on gamma ray shielding features of Pd/Ag-based alloys. Nucl. Eng. Technol. 51, 853-859 (2019). https://doi.org/10.10 16/j.net.2018.12.014

9. E. Şakar, Determination of photon-shielding features and build-up factors of nickel-silver alloys. Radiat. Phys. Chem. 172, 108778 (2020). https://doi.org/10.1016/j.radphyschem.2020.108778

10. F. Akman, M.R. Kaçal, N. Almousa, M.I. Sayyed, H. Polat, Gamma-ray attenuation parameters for polymer composites reinforced with $\mathrm{BaTiO}_{3}$ and $\mathrm{CaWO}_{4}$ compounds. Prog. Nucl. Energy 121, 103257 (2020). https://doi.org/10.1016/j.pnucene.2020.103257

11. K.M. Kaky, M.I. Sayyed, M.H.A. Mhareb, A.H. Abdalsalam, K.A. Mahmoud, S.O. Baki, M.A. Mahdi, Physical, structural, optical and gamma radiation attenuation properties of germanate-tellurite glasses for shielding applications. J. Non. Cryst. Solids. 545, 120250 (2020). https://doi.org/10.1016/j.jnoncrysol.2 020.120250

12. M. Rashad, A.M. Ali, M.I. Sayyed, H.H. Somaily, H. Algarni, Y.S. Rammah, Radiation attenuation and optical features of lithium borate glasses containing barium: $\mathrm{B}_{2} \mathrm{O}_{3} \cdot \mathrm{Li}_{2} \mathrm{O} \cdot \mathrm{BaO}$. Ceram. Int. 46, 21000-21007 (2020). https://doi.org/10.1016/j.ceramint.2020.05.165

13. I. Boukhris, I. Kebaili, M.S. Al-Buriahi, B. Tonguc, M.M. AlShammari, M.I. Sayyed, Effect of bismuth oxide on the optical features and gamma shielding efficiency of lithium zinc borate glasses. Ceram. Int. 46, 22883-22888 (2020). https://doi.org/10.1016/j.ceramint.2020.06.061

14. M.Ç. Ersundu, A.E. Ersundu, N. Gedikoğlu, E. Şakar, M. Büyükyıldız, M. Kurudirek, Physical, mechanical and gamma-ray shielding properties of highly transparent $\mathrm{ZnO}-\mathrm{MoO}_{3}-\mathrm{TeO}_{2}$ glasses. J. Non. Cryst. Solids. 524, 119648 (2019). https://doi.org/10.1016/j.jnoncrysol.2019.119648

15. G. Lakshminarayana, Y. Elmahroug, A. Kumar, N. Rekik, D.E. Lee, J. Yoon, T. Park, Reckoning of nuclear radiation attenuation capabilities for binary $\mathrm{GeO}_{2}-\mathrm{Tl}_{2} \mathrm{O}, \mathrm{GeO}_{2}-\mathrm{Bi}_{2} \mathrm{O}_{3}$, and ternary $\mathrm{GeO}_{2}-\mathrm{Tl}_{2} \mathrm{O}-\mathrm{Bi}_{2} \mathrm{O}_{3}$ glasses utilizing pertinent theoretical and computational approaches. Opt. Mater. (Amst). 108, 110113 (2020). https://doi.org/10.1016/j.optmat.2020.110113

16. M.H.A. Mhareb, Y.S.M. Alajerami, N. Dwaikat, M.S. Al-Buriahi, M. Alqahtani, F. Alshahri, N. Saleh, N. Alonizan, M.A. Saleh, M.I. Sayyed, Investigation of photon, neutron and proton shielding features of $\mathrm{H}_{3} \mathrm{BO}_{3}-\mathrm{ZnO}-\mathrm{Na} 2 \mathrm{O}-\mathrm{BaO}$ glass system. Nucl. Eng. Technol. (2020). https://doi.org/10.1016/j.net.2020. 07.035

17. M. Bengisu, Borate glasses for scientific and industrial applications: a review. J. Mater. Sci. 51, 2199-2242 (2016). https://doi.org/10.1007/s10853-015-9537-4 
18. K.A. Naseer, K. Marimuthu, M.S. Al-Buriahi, A. Alalawi, H.O. Tekin, Influence of $\mathrm{Bi}_{2} \mathrm{O}_{3}$ concentration on barium-telluro-borate glasses: physical, structural and radiation-shielding properties. Ceram. Int. (2020). https://doi.org/10.1016/j.ceramint.2020.08.138

19. E. Kavaz, F.I. El_Agawany, H.O. Tekin, U. Perişanoğlu, Y.S. Rammah, Nuclear radiation shielding using barium borosilicate glass ceramics. J. Phys. Chem. Solids. 142, 109437 (2020). https://doi.org/10.1016/ j.jpcs.2020.109437

20. M.G. Dong, O. Agar, H.O. Tekin, O. Kilicoglu, K.M. Kaky, M.I. Sayyed, A comparative study on gamma photon shielding features of various germanate glass systems. Compos. Part B Eng. 165, 636-647 (2019). https://doi.org/10.1016/j.compositesb.2019.02.022

21. K.A. Naseer, P. Karthikeyan, S. Arunkumar, P. Suthanthirakumar, K. Marimuthu, Enhanced luminescence properties of $\mathrm{Er}^{3+} / \mathrm{Yb}^{3+}$ doped zinc tellurofluoroborate glasses for $1.5 \mu \mathrm{m}$ optical amplification. AIP Conf. Proc. 50, 030237 (2020). https://doi.org/10.1063/5.0019171

22. K.A. Naseer, S. Arunkumar, K. Marimuthu, The impact of $\mathrm{Er}^{3+}$ ions on the spectroscopic scrutiny of Bismuth bariumtelluroborate glasses for display devices and $1.53 \mu \mathrm{m}$ amplification. J. Non. Cryst. Solids. 520, 119463 (2019). https://doi.org/10.1016/j.jnoncrysol.2019.119463

23. J.F. Briesmeister, MCNP-a general Monte Carlo code for neutron and photon transport, version $4 C$ (National Laboratory, Los Alamos, 2000)

24. Q. Chen, K.A. Naseer, K. Marimuthu, P.S. Kumar, B. Miao, K.A. Mahmoud, M.I. Sayyed, Influence of modifier oxide on the structural and radiation shielding features of $\mathrm{Sm}^{3+}$-doped calcium tellurofluoroborate glass systems. J. Aust. Ceram. Soc. (2020). https://doi.org/10.1007/s41779-020-00531-8

25. S. Sindhu, S. Sanghi, A. Agarwal, V.P. Seth, N. Kishore, Effect of $\mathrm{Bi}_{2} \mathrm{O}_{3}$ content on the optical band gap, density and electrical conductivity of $\mathrm{MO} \cdot \mathrm{Bi}_{2} \mathrm{O}_{3} \cdot \mathrm{B}_{2} \mathrm{O}_{3}(\mathrm{M}=\mathrm{Ba}, \mathrm{Sr})$ glasses. Mater. Chem. Phys. 90, 83-89 (2005). https://doi.org/10.1016/j.matchemphys.2004.10.013

26. K.A. Naseer, K. Marimuthu, The impact of $\mathrm{Er} / \mathrm{Yb}$ co-doping on the spectroscopic performance of bismuth borophosphate glasses for photonic applications. Vacuum (2020). https://doi.org/10.1016/j.vacuum.202 0.109788

27. P. Suthanthirakumar, S. Arunkumar, K. Marimuthu, Investigations on the spectroscopic properties and local structure of $\mathrm{Eu}^{3+}$ ions in zinc telluro-fluoroborate glasses for red laser applications. J. Alloys Compd. 760, 42-53 (2018). https://doi.org/10.1016/j.jallcom.2018.05.153

28. M.H.A. Mhareb, M.A. Almessiere, M.I. Sayyed, Y.S.M. Alajerami, Physical, structural, optical and photons attenuation attributes of lithium-magnesium-borate glasses: role of $\mathrm{Tm}_{2} \mathrm{O}_{3}$ doping. Optik (Stuttg). 182, 821-831 (2019). https://doi.org/10.1016/j.ijleo.2019.01.111

29. V. Dimitrov, T. Komatsu, Optical basicity and chemical bonding of $\mathrm{Bi}_{2} \mathrm{O}_{3}$ containing glasses. J. Non. Cryst. Solids. 382, 18-23 (2013). https://doi.org/10.1016/j.jnoncrysol.2013.10.005

30. D.P. Singh, G.P. Singh, Conversion of covalent to ionic behavior of $\mathrm{Fe}_{2} \mathrm{O}_{3}-\mathrm{CeO}_{2}-\mathrm{PbO}-\mathrm{B}_{2} \mathrm{O}_{3}$ glasses for ionic and photonic application. J. Alloys Compd. 546, 224-228 (2013). https://doi.org/10.1016/j.jallcom. 2012.08.105

31. Y.B. Saddeek, S.A.M. Issa, T. Alharbi, R. Elsaman, G. Abdelfadeel, A.M.A. Mostafa, K. Aly, M. Ahmad, Synthesis and characterization of lead borate glasses comprising cement kiln dust and $\mathrm{Bi}_{2} \mathrm{O}_{3}$ for radiation shielding protection. Mater. Chem. Phys. 242, 122510 (2020). https://doi.org/10.1016/j.matchemphys.2 019.122510

32. A. Makishima, J.D. Mackenzie, Direct calculation of Young's moidulus of glass. J. Non. Cryst. Solids. 12, 35-45 (1973). https://doi.org/10.1016/0022-3093(73)90053-7

33. A. Makishima, J.D. Mackenzie, Calculation of bulk modulus, shear modulus and Poisson's ratio of glass. J. Non. Cryst. Solids. 17, 147-157 (1975). https://doi.org/10.1016/0022-3093(75)90047-2

34. A. Abd El-Moneim, Analysis and prediction of elastic moduli and Poisson's ratio in $\mathrm{Li}_{2} \mathrm{O}-\mathrm{B}_{2} \mathrm{O}_{3}-\mathrm{V}_{2} \mathrm{O}_{5}$ glasses under the substitution of $\mathrm{V}_{2} \mathrm{O}_{5}$ for $\mathrm{B}_{2} \mathrm{O}_{3}$. Phys. Chem. Glas. Eur. J. Glas. Sci. Technol. Part B 60, 146-156 (2019). https://doi.org/10.13036/17533562.60.4.001

35. C. Weigel, C. Le Losq, R. Vialla, C. Dupas, S. Clément, D.R. Neuville, B. Rufflé, Elastic moduli of $\mathrm{XAlSiO}_{4}$ aluminosilicate glasses: effects of charge-balancing cations. J. Non. Cryst. Solids. 447, 267-272 (2016). https://doi.org/10.1016/j.jnoncrysol.2016.06.023

36. U. Veit, C. Rüssel, Density and Young's Modulus of ternary glasses close to the eutectic composition in the $\mathrm{CaO}-\mathrm{Al}_{2} \mathrm{O}_{3}-\mathrm{SiO}_{2}$-system. Ceram. Int. 42, 5810-5822 (2016). https://doi.org/10.1016/j.ceramint.20 15.12.123

37. G. Scannell, L. Huang, T. Rouxel, Elastic properties and indentation cracking behavior of $\mathrm{Na}_{2} \mathrm{O}_{-} \mathrm{TiO}_{2}-$ $\mathrm{SiO}_{2}$ glasses. J. Non. Cryst. Solids. 429, 129-142 (2015). https://doi.org/10.1016/j.jnoncrysol.2015.09.0 11

38. T. Rouxel, Elastic properties of glasses: a multiscale approach. Comptes Rendus Mécanique. 334, 743-753 (2006). https://doi.org/10.1016/j.crme.2006.08.001 
39. I.Z. Hager, Effect of $\mathrm{Er}_{2} \mathrm{O}_{3}$ and $\mathrm{ErF}_{3}$ on the structural and elastic properties of sodium oxyfluoroborate glasses. J. Alloys Compd. 539, 256-263 (2012). https://doi.org/10.1016/j.jallcom.2012.06.031

40. M.M. Smedskjaer, J.C. Mauro, S. Sen, J. Deubener, Y. Yue, Impact of network topology on cationic diffusion and hardness of borate glass surfaces. J. Chem. Phys. 133, 154509 (2010). https://doi.org/10.1 063/1.3497036

41. P. Kaur, K.J. Singh, M. Kurudirek, S. Thakur, Study of environment friendly bismuth incorporated lithium borate glass system for structural, gamma-ray and fast neutron shielding properties, Spectrochim. Acta Part A Mol. Biomol. Spectrosc. 223, 117309 (2019). https://doi.org/10.1016/j.saa.2019.117309

42. M.J. Berger, J.H. Hubbell, XCOM: Photon Cross Sections Database, Web Version 1.2., MD 20899, Gaithersburg (1987) 